\title{
Predicting the invasive potential of the cladoceran Daphnia lumholtzi Sars, 1885 (Crustacea: Cladocera: Daphniidae) in the Neotropics: are generalists threatened and relicts protected by their life-history traits?
}

\author{
Francisco DIOGO R. SOUSA, ${ }^{1,2^{*}}$ Alexandre V. PALAORO, ${ }^{3}$ Lourdes M.A. ELMOOR-LOUREIRO,${ }^{1}$ Alexey A. KOTOV ${ }^{4,5}$
}

${ }^{1}$ Laboratório de Ecologia de Ecossistemas, Departamento de Ecologia, Universidade de Brasília, Campus Darcy Ribeiro, CEP 70910900, Brasília, Brazil; ${ }^{2}$ Laboratório de Biodiversidade Aquática, Universidade Católica de Brasília, QS7 lote 1, Bloco M, sala 204, CEP 71966-700, Taguatinga, DF, Brazil; ${ }^{3}$ Núcleo de Estudos em Biodiversidade Aquática, Programa de Pós-graduação em Biodiversidade Animal, Universidade Federal de Santa Maria, Av. Roraima 1000, Camobi, CEP 97105-900, Santa Maria, RS, Brazil; ${ }^{4}$ A.N. Severtsov Institute of Ecology and Evolution, Leninsky Prospect 33, Moscow 119071, Russia; ${ }^{5}$ Kazan Federal University, Kremlevskaya 18, Kazan 420000, Russia

*Corresponding author: fdiogo.rs@gmail.com

\begin{abstract}
Invasive species are one of the major threats to biodiversity, which is aggravated in poorly known groups, such as cladocerans Daphnia lumholtzi Sars (Cladocera: Anomopoda: Daphniidae) is currently invading the Neotropical region, and there are few records of this process. Our goal was to predict the invasive scenario for D. lumholtzi in the Neotropics using species distribution modelling and to assess the climatic overlap of the invader with the native species. We trained our MaxEnt model using occurrence records from native and invaded areas and projected it in the Neotropics. Additionally, we compared the climatic niche of some native species with the invader's niche. Our model showed high environmental suitability in areas connected by the lowland Paraná River Basin (southwestern Brazil, eastern Argentina and Uruguay), in south-central Chile and Atlantic coastal areas. Widely distributed native species showed climatic overlap with the invader, while relict species did not. Daphnia lumholtzi thrives in warm and stable environments (e.g. the Paraná River basin), which of concern because the invader could already be spreading in that area. Native species could suffer due to climatic niche similarity, while natural barriers and local environmental conditions may protect relict species. We urge the need for further studies to understand this invasion process more fully.
\end{abstract}

Key words: Biodiversity conservation; dispersion; invasive species; reservoirs; Paraná River Basin; species distribution model.

Received: September 2016. Accepted: November 2016.

\section{INTRODUCTION}

Invasive species are considered one of the main threats to native ecosystems, because they can cause negative impacts on the stability and evolutionary trends in any community via changes in ecological, behavioral and genetic interactions (e.g., hybridization and introgression; Mooney and Cleland, 2001; Cox, 2004; Simberloff, 2010). To make matters worse, the number of anthropogenic-mediated invasions increased in recent years due to globalization (Perrings et al., 2005; Poulin et al., 2011). The process of biological invasion is fairly complex and can be affected by several factors. The first factor is the capacity of the potential invader to transpose environmental filters, which can interact with the number and frequency of invading propagules (Colautti and McIsaac, 2004). The second factor is the species' capacity to establish itself and spread in novel environments. High adaptability to new conditions is a crucial trait at this stage, because if they cannot adapt to local conditions they can neither establish themselves nor invade (Jímenez-
Valverde et al. 2011; Dobrzycka-Krahel and Graca, 2014; Dobrzycka-Krahel et al., 2015). The third and last factor is the susceptibility of the ecosystem to invasive species (Colautti and McIsaac, 2004; Cox, 2004; Colautti et al., 2006). Due to this inherent complexity, conservation measures employed to mitigate the threat of invasive species need to cover all steps of the invasion process. Consequently, these measures quickly become expensive, highlighting the need for cost-effective measures.

According to Hulme (2006), the most cost-effective measure is preventing the potential invader from establishing itself in the novel environment; these measures are relatively cheap and have a high chance of success, if employed correctly. One tool that can be used to help guide the conservation efforts is species distribution modelling (SDM) (Araujo and Guisan, 2006; Jiménez-Valverde et al., 2008). SDM techniques calculate the environmental space ('climatic niche') of the species based on the environment in which it currently occurs (occurrence records), thus being a portion of the realized niche (Soberón, 2007). This climatic niche can then be projected on to the geo- 
graphic space, including areas in which the species is not currently found (Jiménez-Valverde et al., 2011). If used in the context of biological invasions, SDM can indicate geographical regions that are suitable for a given species, potentially to establish itself and have a positive growth rate (Jiménez-Valverde et al., 2011). Therefore, it offers a framework for conservation strategies to be drawn up more effectively (Guisan et al., 2013). This type of modelling has been used extensively in recent years and has become a useful tool to study invasion ecology (e.g. Peterson, 2003; Nori et al., 2011; Palaoro et al., 2013; Campbell et al., 2015; Marcantonio et al., 2016). Another source of evidence we can use to predict the impact of the invader is to compare the invader's climatic niche with that of a native species. If native and invasive species have similar climatic niches, it is possible that they may compete for resources on a smaller scale, creating further disturbances for native species (Palaoro et al., 2013).

Neotropical biodiversity has been considered vulnerable to invasive species, with many groups of native plants and animals - especially freshwater organisms threatened by extinction due to the activity of invasive species (Rodríguez, 2001; Clavero and García-Berthou, 2005; Speziale and Lambertucci, 2010). A particularly striking example is the thermophilic cladoceran Daphnia (Ctenodaphnia) lumholtzi Sars, 1885 (Crustacea: Cladocera: Daphniidae). This species complex is native to southern Asia, Australia and Africa (Kotov and Taylor, 2014), but it successively invaded North America in the 1990's (Havel and Hebert, 1993; Havel et al., 2000; Havens et al., 2000). Although Havens et al. (2012) indicated no evidence for competitive exclusion of native cladocerans by invasive species in lakes of North America, experimental studies showed that $D$. lumholtzi is able to tolerate a wide range of temperature variation (Brown, 1999; Johnson and Havel 2001; Fey and Cottinghan, 2012) and that, in the presence of predators, D. lumholtzi increases its investment in reproduction, becoming a stronger competitor when compared to native species (Dzialowski et al., 2003). In invaded habitats, D. lumholtzi might suppress native species at least seasonally (Dobberfuhl and Elser, 2002). So far, there is no consistent information on the influence of $D$. lumholtzi on the provision of ecosystem services in invaded habitats, or of economic impacts of the invasion process.

After the establishment of the first populations in North America (Havel and Hebert, 1993), a rapid colonization proceeded (Dzialowski et al., 2003). Soon after that, D. lumholtzi was reported in Mexico (Eliás-Gutierréz et al., 2008; Silva-Briano et al., 2010), Brazil (Zanata et al., 2003; Simões et al., 2009) and, more recently, Argentina (Kotov and Taylor, 2014). A darker scenario emerges when we realize these records are distant from each other, both in space and time - thus not enough sam- pling has been done, and the situation in the Neotropics may be significantly underestimated. Of all Daphnia species with exclusive occurrence in the Neotropics (see Kotov et al., 2013), only D. gessneri Herbst, 1967 has a wide distribution range. At least five other Daphnia species are endemic to a few water bodies or even a single one (Hann, 1986; Valdivia-Vilar and Burger, 1989; Kotov et al., 2010), thus being considered geographical relicts (sensu Grandcolas et al., 2014). This is troubling, since a high level of endemism usually correlates with environmental specificity, which increases the risk of functional and local extinction (Carlton et al., 1999; Sodhi et al., 2009). Therefore, the invasion of $D$. lumholtzi increases the potential risk of extinction for the Neotropical Daphnia, which makes understanding the invasive potential of D. lumholtzi even more necessary.

In this study, we used SDM to predict the invasion scenario for $D$. lumholtzi in the Neotropics. We used occurrence records of this species (including both native and invaded areas) to build a model and then project it in the Neotropics. In addition, we checked if $D$. lumholtzi and the endemic Neotropical species of Daphnia occupy similar, or significantly overlapping, climatic niches.

\section{METHODS}

We found 137 occurrence records of $D$. lumholtzi in different locations throughout the world (Fig. 1). These data were obtained from the Global Biodiversity Information Facility (GBIF) (http://www.gbif.org), United States Geological Survey (USGS, 2012) and from different previously published literature sources (Supplementary References). We did not include records from the Caspian region, because it represents a separate species initially described as Daphnia lumholtzi palaeartica Behning, 1928. It has obvious morphological differences from $D$. lumholtzi and has a distinct life-history, i.e. it is adapted to cooler temperatures than its congeners (Behning, 1941).

To build the SDM, we did not distinguish between records of native and invaded populations, because invasive species may violate two premises of SDMs: i) the invasion process may not be complete; ii) the niche may change in novel habitats (Peterson, 2003; Guisan and Thuiller, 2005; Broennimann et al., 2007; JiménezValverde et al., 2011). The recommended method to overcome these issues is to include both the native and invaded ranges, since these models how better performances than models using only the native range (Broennimann and Guisan, 2008; Beaumont et al., 2009; Capinha et al., 2011). The SDM was performed using eight climatic variables taken from the Wordclim database (Hijmans et al., 2005) (download: http://www.worldclim.org) and one topographic variable (Breakline emphasis GMTED2010) at a spatial resolution of 30 arc-seconds 
(Tab. 1). These variables were chosen because they were not highly correlated (Pearson's $r<|0.9|$ ). According to Jiménez-Valverde et al. (2011), it is also necessary to consider the biological relevance of the variables chosen. Thus, all variables used to build the SDM are related with features from the biology or ecology of the cladoceran species (Tab. 1).

Maximum entropy modelling (MaxEnt) is a machine learning method that is considered the most robust method for predicting environmental suitability using presenceonly data. The advantages of this method are: i) mathematical functions are concise and the results are easily interpreted (Phillips et al., 2006; De Marco and Siqueira, 2009); and ii) MaxEnt can make accurate predictions using a reduced set of occurrence records (Costa et al., 2010). When compared to other SDM techniques, MaxEnt was among the most effective when using presenceonly data, with a performance comparable to techniques that use presence and absence data (Elith et al., 2006; Costa et al., 2010). Thus, we chose MaxEnt to model the environmental suitability of $D$. lumholtzi in the Neotropics. We used occurrence records from both native and invaded areas to calibrate the model, which was then projected to the Neotropical region, following the sugges-

Tab. 1. Variables used to build the species distribution model of Daphnia lumholtzi from native and invaded areas, and the relative contribution of each environmental variable to the model.

\begin{tabular}{|c|c|c|}
\hline Variable (data source) & Contribution ( $\%)$ & Justification \\
\hline Breakline emphasis (GMTED2010, be30_grd) & 4.8 & $\begin{array}{l}\text { Topographic variable is important for delimitation of rivers, streams, } \\
\text { ponds and floodplains }\end{array}$ \\
\hline Annual Mean Temperature (Worldclim, bio_1) & 20.8 & \\
\hline Isothermality (WorldClim, bio_3) & 17 & \\
\hline Temperature Seasonality (WorldClim, bio_4) & 8.5 & \\
\hline Temperature annual range (WorldClim, bio_7) & 5.6 & Temperature and precipitation are linked to homeostasis and \\
\hline Mean Temperature of Warmest Quarter (WorldClim, bio_10) & 2.7 & \\
\hline Precipitation of driest quarter (WorldClim, bio_17) & 2.6 & \\
\hline Precipitation of coldest quarter (WorldClim, bio_19) & 2.3 & \\
\hline
\end{tabular}

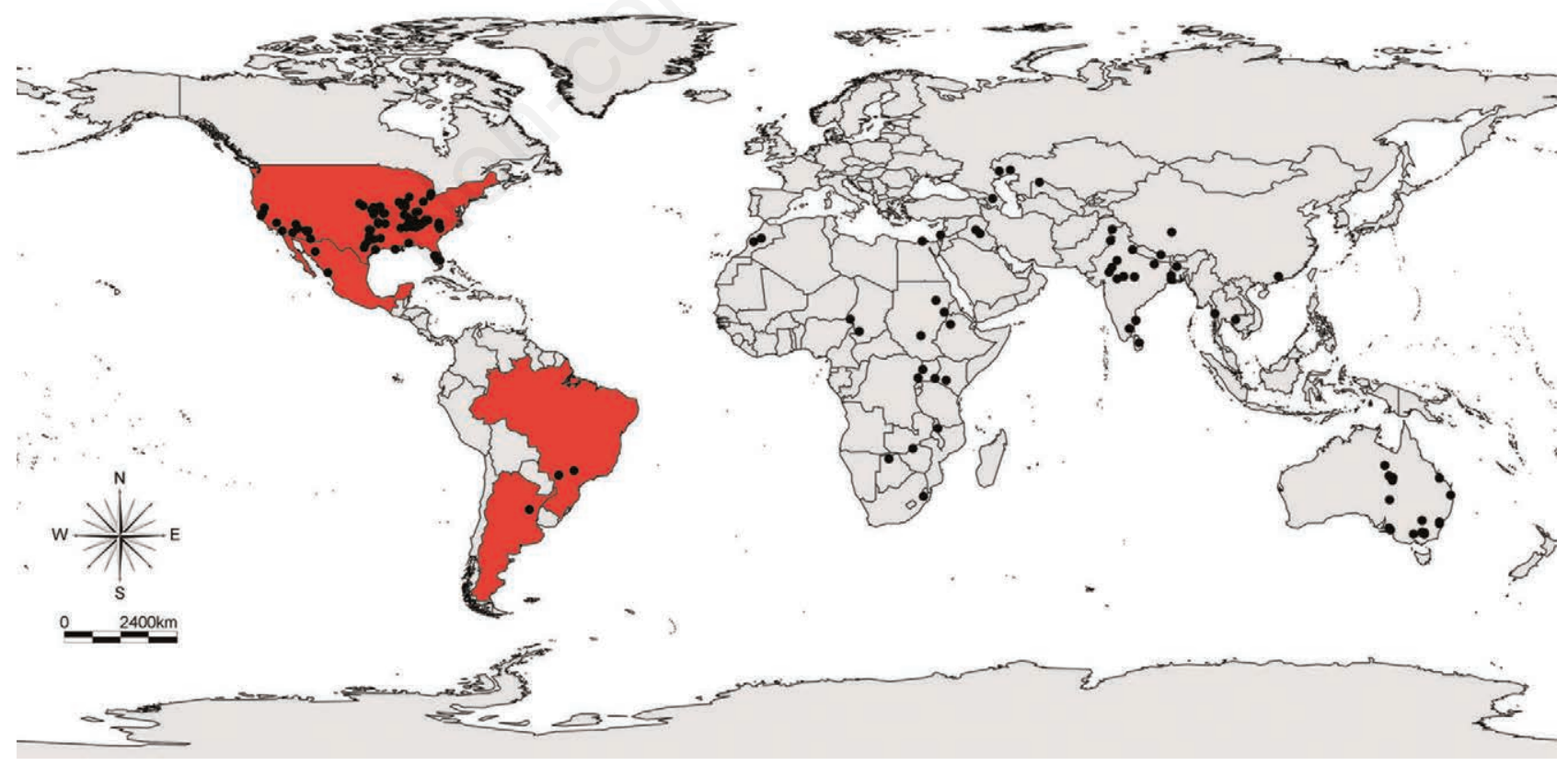

Fig. 1. Records of Daphnia lumholtzi used in our species distribution model based on data from both native and invaded areas. Invaded countries in North and South America are presented in red. Data obtained from Global Biodiversity Information Facility (GBIF) (http://www.gbif.org), United State Geological Survey (USGS, 2012) and from published literature (see Supplementary References). 
tion of Peterson (2003) and Jimenéz-Valverde et al. (2011). A cross-validation with 10 replications was used to estimate errors of adjusted functions and the predictive power of data held for testing (Palaoro et al., 2013). The SDM for D. lumholtzi was assessed using the area under the receiver-operating characteristic curve (AUC). The AUC provides a threshold independent measure of model performance compared to null expectations. It has been used to assess SDMs due to the evaluation of specificity (absence of commission errors) and sensitivity (absence of omission errors) (Elith et al., 2006). If AUC values are close to 1, they indicate a good performance of the SDM. To help in the interpretation of results we followed the suggestion of Palaoro et al., (2013), as follows: AUC $>0.9=$ excellent; $0.8>$ AUC $<0.9=$ good; $0.7>$ AUC $<0.8=$ fair; $0.6>$ AUC $<0.7=$ bad; AUC $<0.6=$ failed.

To observe if the climatic niche of $D$. (Ctenodaphnia) lumholtzi may overlap with that of native species of the genus, we obtained the occurrence records of $D$. (Daphnia) gessneri Herbst, 1967, D. (D.) peruviana Harding, 1955, D. (D.) marcahuasensis Valdivia-Villar \& Burger, 1989, D. (Ctenodaphnia) chilensis (Hann, 1986), D. (C.) dadayana (Paggi, 1999), D. (C.) inca Korinek \& Villalobos, 2003, D. (C.) menucoensis Paggi, 1996, D. (C.) ornithocephala Baribén, 1953, D. (C.) paggii Kotov, Sinev $\&$ Berrios, 2010, D. (C.) spinulata Baribén, 1917. Due to the uncertainty of several occurrence records in the literature, we checked all native species on the List of Cladocera of the World to ascertain that they are only endemic in the Neotropics (Kotov et al., 2013).

After that, we gathered the environmental variable values for each occurrence record of the native species and D. lumholtzi and transformed the data using ranging transformation:

$$
\left[\left(\mathrm{x}-\min _{\mathrm{x}}\right) /\left(\max _{\mathrm{x}}-\min _{\mathrm{x}}\right)\right]
$$

Lastly, we performed an ordination analysis (principal components analysis - PCA) using a covariance matrix. Data were analyzed in the Software PAST (Hammer et al., 2001).

\section{RESULTS}

The calibrated model had a mean AUC of $0.884 \pm 0.03$, suggesting a good model (Fig. 2). The projection showed high suitability in the regions connected by the Paraná River Basin between southwestern Brazil, eastern Argentina and Uruguay (Fig. 2). High suitability was also found in South-central Chile, coastal areas of Brazil (Atlantic coast) and Mexico (Fig. 2).

PCA axis 1 (PC1) explained $54.48 \%$ of the variance with an eigenvalue of 0.16 , while axis 2 (PC2) explained $18.17 \%$ of the variance with an eigenvalue of 0.05 . The ordination presented a clear gradient related to climatic variables (from the right to the left) with $D$. spinulata, $D$. menucoensis, $D$. dadayana, $D$. ornithocephala and $D$. gessneri showing different degrees of overlap with $D$. lumholtzi (Fig. 3 A,C,D, G,H,K). In contrast, D. lumholtzi does not overlap with species that are endemic to mountainous regions, i.e. D. chilensis, D. inca, D. marcahuasensis, $D$. paggii and $D$. peruviana (Fig. 3 A,B,E,F,I,). The most important variables $(r>|0.7|)$ observed were isothermality $(r=-0.94)$, temperature seasonality $(r=0.98)$, temperature annual range $(r=0.95)$ for PC1, and precipitation of the driest quarter $(r=-0.73)$ for $\mathrm{PC} 2$.

\section{DISCUSSION}

Our results showed that $D$. lumholtzi has the potential to invade large portions of the Neotropics that are not yet colonized (or regarded as not yet colonized due to insufficient sampling). We highlight the high environmental suitability of D. lumholtzi in Argentina, Chile and Uruguay, which should increase the probability of invasion in many water bodies in that region (Fig. 2; Sousa et al., 2014). This result is worrying, because $D$. lumholtzi disperses both adults and resting eggs (in the ephippia) via lotic systems, and uses stagnant water bodies - such as reservoirs and dams - to establish viable populations (Panov et al., 2004: Havel and Medley, 2006). These lowland man-made reservoirs are more susceptible to invasions when compared to natural water bodies, because they function as stepping stones for the invaders (Havel et al., 2005, 2015; Johnson et al., 2008). The main issue is that the Paraná River basin, the most vulnerable area for the invasion of $D$. lumholtzi according to our model, connects three countries on a large spatial scale by lotic and flood systems with periodic hydrological cycles - also presenting numerous dams and reservoirs. Due to this, the population found in Argentina by Kotov and Taylor (2014) could have come originally from Brazil, since the first reports in South America come from there (Zanata et al., 2003; Simões et al., 2009). Further colonization of the Neotropics could occur by dispersion via water currents (e.g. the Argentinian population) or by waterfowl (i.e., carrying the ephippia on their feathers and through midgut passage; Incagnone et al., 2015).

Daphnia lumholtzi shows a considerable climatic niche overlap with some native lowland species (Fig. 3). Havens et al. (2012) indicate no evidence of the competitive exclusion of native species by $D$. lumholtzi invaders in lakes of North America. However, some key sources of evidence show why $D$. lumholtzi may negatively affect native Daphnia species. Daphnia lumholtzi has a relatively higher fitness in warmer waters when compared to other Daphnia species (Kolar et al., 1997; Work and Gophen, 1999; Lenon et al., 2001; Wittmann et al., 2013). In addition, $D$. lumholtzi increases its reproductive effort when exposed to predators (Dzialowski et al., 2003) and 
develops a long and strong helmet and tail spine, serving as a mechanism to reduce predation, causing difficulties to invertebrate predators and even fish larvae (Engel and Tollrian, 2009; Engel et al., 2014).

In the Indian subcontinent, Padhye et al., (2016) indicated that the distribution of $D$. lumholtzi was associated with localities that show warm and stable temperatures.
Likewise, the relatively higher temperatures and higher stability of lowland Neotropical ecosystems when compared to temperate ecosystems would thus increase any competitive advantage of $D$. lumholtzi over the native species (McMahon, 2002). This was supported by the PCA, where isothermality (related to climatic stability) and temperature seasonality (related to climatic seasonal-
- Reported populations

Lower suitability

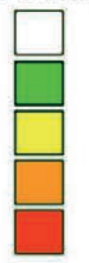

Higher suitability
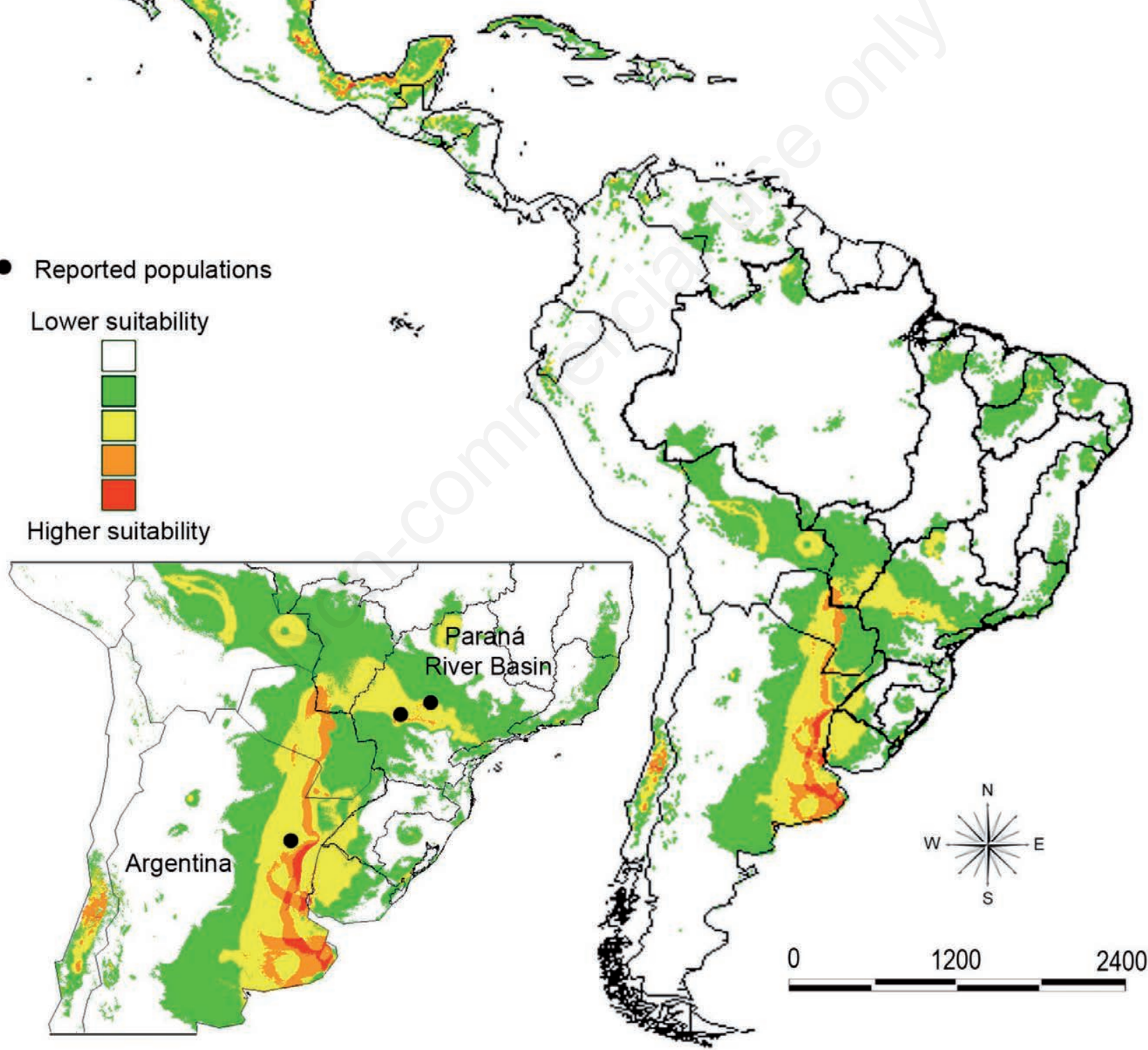

Fig. 2. Environmental suitability of the invader Daphnia lumholtzi in the Neotropics. The model was calibrated using native and invaded occurrence records, then projected to the Neotropical region (AUC: $0.884 \pm 0.03$ ). Brazil is subdivided in hydrographical regions (Resolution number 32 of the National Council of Hydric Resources). Warmer colors indicate higher environmental suitability. 
ity) seem to be responsible for the ordination of $D$. lumholtzi to D. chilensis, D. inca, D. marcahuasensis, $D$. paggii, D. peruviana (Fig. 3 A,B,D,E,F,I,J). These five mountainous endemics do not show a climatic niche overlap with $D$. lumholtzi. However, D. lumholtzi may also influence these native species via niche expansions or shifts that may occur during the invasion process (e.g., predator release effect, niche shifts; Capinha et al., 2011; Petitpierre et al., 2012).
If widely distributed lowland species are more vulnerable to the invader, endemic species of Daphnia may be protected against such a fate by natural barriers and unusual (extreme) environmental conditions. At least some South American endemic daphniids with very local distribution could be regarded as relicts (Kotov et al., 2010). Relicts, usually occurring in extreme habitats, are extinction-prone due to environmental disturbances caused by human activity (Pitman et al., 2002; Lavergne et al., 2006;
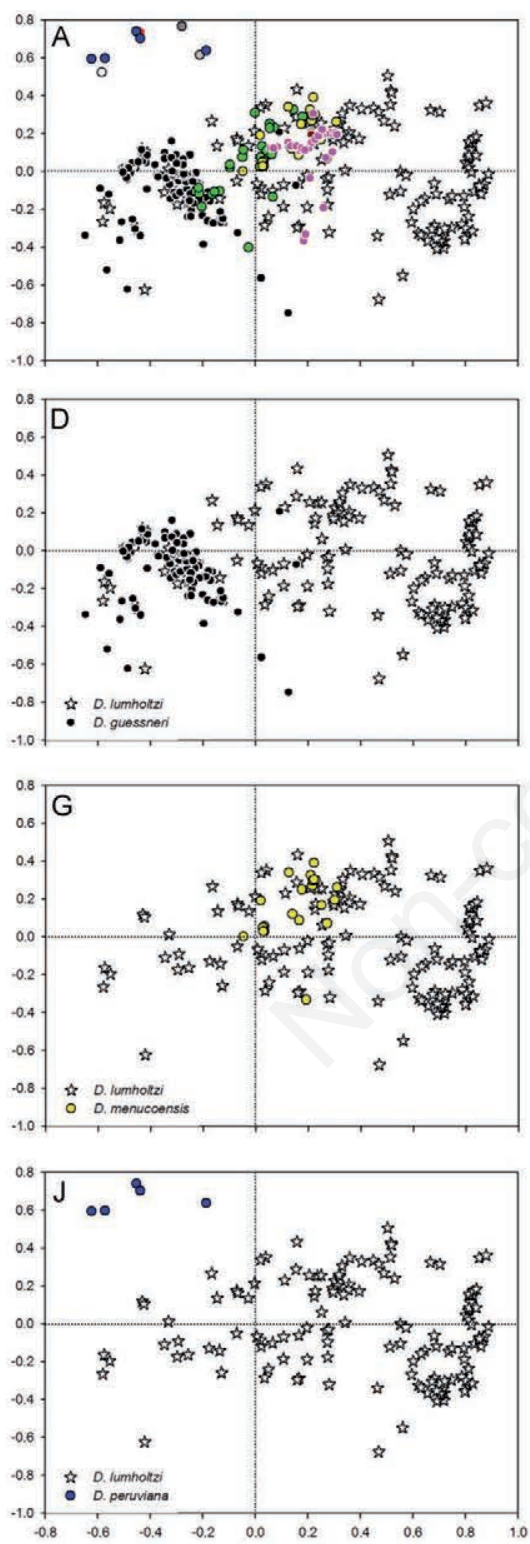
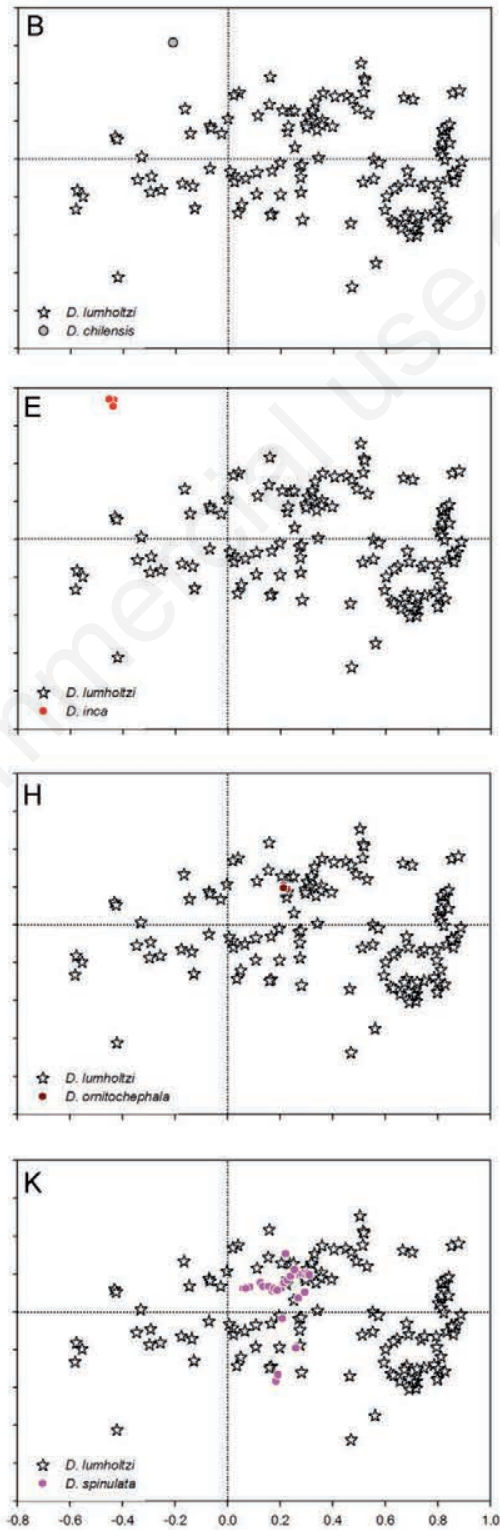
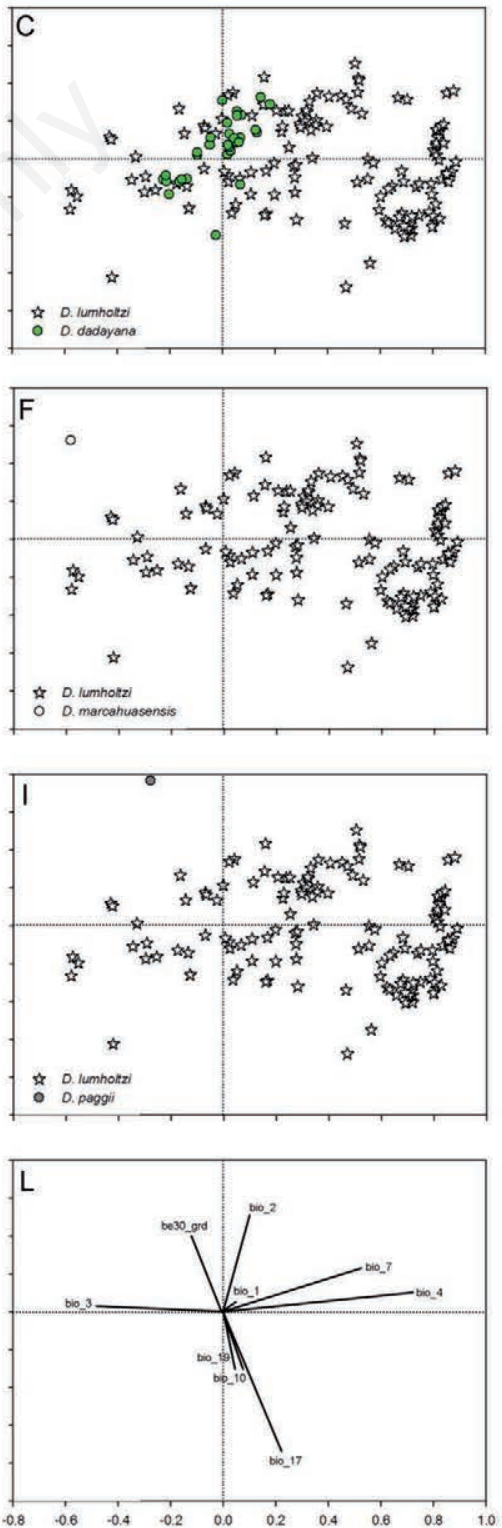

Fig. 3. A) Biplot of principal components analysis, which was made with eight climatic and one topographic variable (see Tab. 1). The first and the second axis explain more than $70 \%$ of the observed variance. B-K) Ordination of native versus invasive species. L) Vectors from climatic variables. Daphnia chilensis (B), D. inca (E), D. marcahuasensis (F), D. paggii (I) and D. peruviana (J). Daphnia lumholtzi presents a high climatic niche overlap with most of the native species - except for D. chilensis (B), D. inca (E), D. marcahuasensis (F), D. paggii (I) and D. peruviana $(\mathrm{J})$. 
Chambers et al., 2008). Paradoxically, we found that locally distributed relicts may be better protected against invaders due to the climatic and geographic singularities in which they occur. Zhang et al. (2016) showed that geographic isolation was an important predictor of the distribution pattern of relict populations of the plant Emmenopterys henryi Oliv. (Rubiaceae). In the case of Neotropical relict Daphnia species, current geographic isolation provided by mountains (especially the Andes) can be an important barrier to prevent propagule pressure of $D$. lumholtzi from the lowlands. Indeed, the connections between aquatic systems (especially man-made) and their position in the landscape seems to have a primary and important role in the invasion process of D. lumholtzi in North and South American lowlands (Havel and Medley, 2006; Simões et al., 2009). Unfortunately, such barriers are not effective in the case of occasional or deliberate human-mediated dispersion.

Another factor that was not covered in the model is UV radiation, which is very strong in the highlands. Most mountainous endemic species are strongly pigmented (Benzie, 2005; Kotov et al., 2010) to protect themselves against UV radiation. The situation in the Neotropics could be similar to that in water bodies of the African Rift Valley, where 'aggressive' American clones of $D$. cf. pulex replaced the native daphniids in many lowland water bodies (Mergeay et al., 2005a, 2005b, 2006) but did not impact the endemic species, D. izpodvala, which inhabits the Bale Mountains. Daphnia izpodvala Kotov \& Taylor, 2010 is strongly pigmented, while $D$. cf. pulex is not able to produce such melanin pigmentation (Kotov and Taylor, 2010).

\section{CONCLUSIONS}

Our results represent the first approach using modelling distribution of $D$. lumholtzi on a large spatial scale. Landscape features, higher temperatures and climatic stability in lowlands may facilitate the invasion process of $D$. lumholtzi due to the connectivity of lotic systems, presence of man-made water bodies, and higher fitness of the invader in warmer and more stable climates. In the Neotropics, generalist species, such as D. gessneri, might be relatively more threatened by the invasion process than other species. Daphnia lumholtzi and D. gessneri already co-occur in the Paraná River Basin (Zanata et al., 2008; Simões et al., 2009). Meanwhile, the other relict species seem to be protected from the invader due to the geographic isolation and local conditions of their habitats, features that may prevent $D$. lumholtzi's establishment in the region. Regarding future studies, in vulnerable regions, such as the coastal regions of Brazil and Mexico, we urge for a continuous monitoring of the cladoceran fauna. In the regions already invaded by $D$. lumholtzi we recommend further studies so we can fully understand the extent of the current invasion. More studies on how the invader may affect native species, either via ecological (e.g., the interaction between the species) or evolutionary studies (e.g., behavior, genetic studies), are also needed. The co-occurrence of $D$. lumholtzi and $D$. gessneri in the Paraná River Basin seems particularly interesting for this purpose. It is also necessary to emphasize that the water bodies where the relict species occur are located in areas that have experienced minimal human disturbance. By keeping them preserved, the risk of occasional introduction of $D$. lumholtzi ephippia in those environments decreases, thus protecting the relict taxa.

\section{ACKNOWLEDGMENTS}

We thank CAPES for the doctoral scholarship to AVP and the Russian Government Program of Competitive Growth of Kazan Federal University for supporting AAK. We also thank Dr. Marcelo M. Dalosto and Susan Casement Moreira for revising the English version of this manuscript and two anonymous reviewers for their valuable suggestions, which have improved the manuscript.

\section{REFERENCES}

Araujo MB, Guisan A, 2006. Five (or so) challenges for species distribution modelling. J. Biogeogr. 33:1677-1688.

Beaumont LJ, Gallagher RV, Thuiller W, Downey PO, Leishmann MR, Hughes L, 2009. Different climatic envelopes among invasive populations may lead to underestimations of current and future biological invasion. Divers. Distrib. 15:409-420.

Behning AL, 1941. The Cladocerans of the Caucasus. Gruzmedgiz Publishing, Tbilisi: 383 pp.

Benzie JAH, 2005. Cladocera: The genus Daphnia (including Daphniopsis) (Anomopoda: Daphniidae). Backhuys Publishers, Leiden: $376 \mathrm{pp}$.

Broennimann O, Guisan A, 2008. Predicting current and future biological invasions: both native and invaded ranges matter. Biol. Lett. 4:585-589.

Broennimann O, Treier U.A, Meuller-Schearer H, Thuiller W, Peterson AT, Guisan A, 2007. Evidence of climatic niche shift during biological invasion. Ecol. Lett.10:701-709.

Brown RS, 1999. Aspects of the biology of Daphnia lumholtzi (Sars) in Ft. Loudoun Reservoir, Tennessee. Ph.D. Thesis, University of Tennessee, Knoxville.

Campbell LP, Luther C, Moo-Llanes D, Ramsey JM, DanisLozano R, Peterson AT, 2015. Climate change influences on global distributions of dengue and Chikungunya virus vectors. Phil. T. R. Soc. B. 370:20140135.

Capinha C, Leung B, Anastacio P, 2011. Predicting worldwide invasiveness for four major problematic decapods: an evaluation of using different calibration sets. Ecography 34:448-459.

Carlton JT, Geller JB, Reaka-Kudla ML, Norse EA, 1999. Historical extinctions in the sea. Ann. Rev. Ecol. Syst. 30:515-538.

Chambers PA, Lacoul P, Murphy KJ, Thomaz SM, 2008. Global 
diversity of aquatic macrophytes in freshwater. Hydrobiologia 595:9-26.

Clavero M, García-Berthou E, 2005. Invasive species are a leading cause of animal extinctions. Trends Ecol. Evol. 20: 110.

Colautti RI, MacIsaac HJ, 2004. A neutral terminology to define 'invasive' species. Divers. Distrib. 10:135-141.

Colautti RI, Bailey SA, van Overdijk CDA, Admunsen K, MacIsaac HJ, 2006. Characterised and projected costs of nonindigenous species in Canada. Biol. Invasions 8:45-59.

Costa GC, Nogueira C, Machado RB, Colli GR, 2010 Sampling bias and the use of ecological niche modeling in conservation planning: a field evaluation in a biodiversity hotspot. Bio. Conserv. 19:883-899.

Cox GW, 2004. Alien species and evolution. Island Press, Washington DC: $400 \mathrm{pp}$.

De Marco JRP, Siqueira MF, 2009. [Como determinar a distribuição de espécies sobre uma abordagem conservacionista].[Article in Portuguese]. Megadiversidade 5:65-769.

Dobberfuhl DL, Elser JJ, 2002. Distribution and potential competitive effects of an exotic zooplankter (Daphnia lumholtzi) in Arizona reservoirs. J. Arizona-Nevada Acad. Sci. 34:89-94.

Dobrzycka-Krahel A, Graca B, 2014. Laboratory study of the effect of salinity and ionic composition of water on the mortality and osmoregulation of the gammarid amphipod Dikerogammarus haemobaphes (Eichwald, 1841): implications for understanding its invasive distribution pattern. Mar. Freshwater Res. 47:227-238.

Dobrzycka-Krahel A, Melzer M, Majkowski W, 2015. Range extension of Dikerogammarus villosus (Sowinsky, 1894) in Poland (the Baltic Sea basin) and its ability to osmoregulate in different environmental salinities. Oceanol. Hydrobiol. St. 44: 94-304.

Dzialowski AR, Lennon JT, O'Brien WJ, Smith VH, 2003. Predator-induced phenotypic plasticity in the exotic cladoceran Daphnia lumholtzi. Freshwater Biol. 48:1593-1602.

Eliás-Gutiérrez M, Martínez-Jerónimo F, Ivanova NV, ValdezMoreno M, Hebert PDN, 2008. DNA barcodes for Cladocera and Copepoda from Mexico and Guatemala, highlights and new discoveries. Zootaxa 1839:1-42.

Elith J, Graham CH, Anderson RP, Dudık M, Lohmann LG, Loiselle BA, Manion G, Moritz C, Nakamura M, Nakazawa Y, Overton JMcCM, Townsend Peterson A, Phillips SJ, Richardson K, Scachetti-Pereira R, Schapire RE, Soberón J, Williams S, Wisz MS, Zimmermann NE, 2006. Novel methods improve prediction of species' distributions from occurrence data. Ecography 29:129-151.

Engel K, Tollrian R, 2009. Inducible defences as key adaptations for the successful invasion of Daphnia lumholtzi in North America? P. Roy. Soc. Lond. B-Biol. 276:1865-1873.

Engel K, Schreder T, Tollrian R, 2014. Morphological defences of invasive Daphnia lumholtzi protect against vertebrate and invertebrate predators. J. Plankton. Res. 36:1140-1145.

Fey SB, Cottingham KL, 2012. Thermal sensitivity predicts the establishment success of non-native species in a mesocosm warming experiment. Ecology 93:2313-2320.

Grandcolas P, Nattier R, Trewick S, 2014. Relict species: a relict concept? Trends Ecol. Evol. 29:655-663.

Guisan A, Thuiller W, 2005. Predicting species distribution: offering more than simple habitat models. Ecol. Lett. 8:993-1009.

Guisan A, Baumgartner JB, Naujokaitis-Lewis I, Sutcliffe RP,
Tulloch AIT, Regan TJ, Brotons L, McDonald-Madden E, Mantyka-Pringle C, Martin TG, Rhodes JR, Maggini R, Setterfield SA, Elith J, Schwartz MW, Wintle BA, Broennimann O, Austin M, Ferrier S, Kearney MR, Possingham HP, Buckley YM, 2013. Predicting species distributions for conservation decisions. Ecol. Lett. 16:1424-1435.

Hammer Ø, Harper DAT, Ryan PD, 2001. PAST: Paleontological Statistics Software Package for education and data analysis. Palaeontol. Electron. 4:1-9.

Hann BJ, 1986. Revision of the genus Daphniopsis Sars, 1903 and description of Daphniopsis chilensis, new species from South America. J. Crustacean Biol. 6:246-263.

Havel JE, Hebert PDN, 1993. Daphnia lumholtzi in North America: another exotic zooplankter. Limnol. Oceanogr. 38:18231827.

Havel JE, Medley KA, 2006. Biological invasions across spatial scales: intercontinental, regional, and local dispersal of cladoceran zooplankton. Biol. Invasions. 8:459-473.

Havel JE, Colbourne JK, Hebert PDN, 2000. Reconstructing the history of intercontinental dispersal in Daphnia lumholtzi by use of genetic markers. Limnol. Oceanogr. 45: 1414-1419.

Havel JE, Lee CE, Zanden MJV, 2005. Do reservoirs facilitate invasions into landscapes? BioScience 55:518-525.

Havel JE, Kenko KE, Thomaz SM, Amalfitano S, Kats LB, 2015. Aquatic invasive species: challenges for the future. Hydrobiologia 750:147-170.

Havens KE, East TL, Marcus J, Essex P, Bolan B, Raymond S, et al., 2000. Dynamics of the exotic Daphnia lumholtzi and native macro-zooplankton in a subtropical chain-of-lakes in Florida, U.S.A. Freshwater Biol. 45:21-32.

Havens KE, Beaver JR, East TL, Work K, Phlips DJ, Cichra MF, Croteau AC, Rodusky AJ, Fulton RS, Rosati TC, 2012. The outcome of the invasion of Florida lakes by Daphnia lumholtzi. Freshwater Biol. 57: 552-562.

Hijmans RJ, Cameron SE, Parra JL, Jones PG, Jarvis A, 2005. Very high resolution interpolated climate surfaces for global land areas. Int. J. Climatol. 25:1965-1978.

Hulme PE, 2006. Beyond control: wider implications for the management of biological invasions. J. Appl. Ecol. 43:835-847.

Incagnone G, Marrone F, Barone R, Robba L, Naselli-Flores L, 2015. How do freshwater organisms cross the "dry ocean"? A review on passive dispersal and colonization processes with a special focus on temporary ponds. Hydrobiologia 750:103-123.

Jiménez-Valverde A, Lobo JM, Hortal J, 2008. Not as good as they seem: the importance of concepts in species distribution modelling. Divers. Distrib. 14:885-890.

Jimenez-Valverde A, Peterson AT, Sobéron J, Overton JM, Aragon P, Lobo JM, 2011. Use of niche models in invasive species risk assessments. Biol. Invasions 13:2785-2797.

Johnson JL, Havel JE, 2001. Competition between native and exotic Daphnia: in situ experiments. J. Plankton Res. 23: 373-387.

Johnson PTJ, Olden JD, Vander Zanden MJ, 2008. Dam invaders: impoundments facilitate biological invasions into freshwaters. Front. Ecol. Environ. 6:357-363.

Kolar CS, Boase JC, Clapp DF, Whal DH, 1997. Potential effect of invasion by an exotic zooplankter, Daphnia lumholtzi. J. Freshwater Ecol. 12:521-530.

Kotov AA, Taylor DJ, 2010. A new African lineage of the Daph- 
nia obtusa group (Cladocera: Daphniidae) disrupts continental vicariance patterns. J. Plankton Res. 32:937-949.

Kotov AA, Taylor DJ, 2014. Daphnia lumholtzi Sars, 1885 (Cladocera: Daphniidae) invades Argentina. J. Limnol. 73:364-374.

Kotov AA, Sinev AY, Berrios VL, 2010. The Cladocera (Crustacea: Branchiopoda) of six high altitude water bodies in the North Chilean Andes, with discussion of Andean endemism. Zootaxa 2430:1-66.

Kotov AA, Forró L, Korovchinsky NM, Petrusek A, 2013. World checklist of freshwater Cladocera species. World Wide Web electronic publication. Available from: http:// fada.biodiversity.be/group/show/17

Lavergne S, Molina J, Debussche MAX, 2006. Fingerprints of environmental change on the rare mediterranean flora: a 115-year study. Glob. Change Biol. 12: 466-1478.

Lenon JT, Smith VH, Williams K, 2001. Influence of temperature on exotic Daphnia lumholtzi and implications for invasion success. J. Plankton Res. 23:25-434.

Marcatonio M, Mets M, Baldachino F, Arnoldi D, Montarsi F, Campelli G, Carlin S, Neteler M, Rizzoli A, 2016. First assessment of potential distribution and dispersal capacity of the emerging invasive mosquito Aedes koreicus in Northeast Italy. Parasit. Vectors. 9:63.

McMahon RF, 2002. Evolutionary and physiological adaptation of aquatic invasive animal: $r$ selection versus resistance. Can. J. Fish. Aquat. Sci. 59:1235-1244.

Mergeay J, Verschuren D, De Meester L, 2005a. Cryptic invasion and dispersal of an American Daphnia in East Africa. Limnol. Oceanogr. 50:1278-1283.

Mergeay J, Verschuren D, De Meester L, 2005b. Daphnia species diversity in Kenya, and a key to the identification of their ephippia. Hydrobiologia. 542:261-274.

Mergeay J, Verschuren D, De Meester L, 2006. Invasion of an asexual American water flea clone throughout Africa and rapid displacement of a native sibling species. P. Roy. Soc. Lond. B-Biol. 273:2839-2844.

Mooney HA, Cleland EE, 2001. The evolutionary impact of invasive species. Proc, Nat. Acad. Sci. USA. 98: 5446-5451.

Nori J, Urbina-Cardona JN, Loyola RD, Lescano JN, Leynaud GC, 2011. Climate change and American bullfrog invasion: what could we expect in South America? PLoS One 6:e25718.

Padhye SM, Kotov AK, Dahanukar N, Dumont HJ, 2016. Biogeography of Daphnia O. F. Müller (Crustacea: Branchiopoda: Anomopoda) on the Indian subcontinent. J. Limnol. 75:571-580.

Palaoro AV, Dalosto MM, Costa GC, Santos S, 2013. Niche conservatism and the potential for the crayfish Procambarus clarkii to invade South America. Freshwater Biol. 58:1379-1391.

Panov VE, Krylov PI, Riccardi N, 2004. Role of diapause in dispersal and invasion success by aquatic invertebrates. J. Limnol. 63:56-69.

Perrings C, Dehnen-Schmutz K, Touza J, Williamson M, 2005. How to manage biological invasions under globalization. Trends Ecol. Evol. 20:212-215.

Peterson AT, 2003. Predicting the geography of species' invasions via ecological niche modeling. Q. Rev. Biol. 78:419-433.

Petitpierre B, Kueffer C, Broennimann O, Randin C, Daehler C, Guisan A, 2012, Climatic niche shifts are rare among terrestrial plant invaders. Science 335:1344-1348.
Phillips SJ, Anderson RP, Schapire RE, 2006. Maximum entropy modeling of species geographic distributions. Ecol. Modell. 190:231-259.

Pitman NC, Jørgensen PM, Williams RS, León-Yánez S, Valencia R, 2002. Extinction-Rate Estimates for a Modern Neotropical Flora. Conser. Biol. 16:1427-1431.

Poulin R, Paterson RA, Townsend CR, Tompkins DM, Kelly DW, 2011. Biological invasions and the dynamics of endemic diseases in freshwater ecosystems. Freshwater Biol. 56:676-688.

Rodríguez JP, 2001. Exotic species introductions into South America: an underestimated threat? Biod. Conserv. 10:1983-1996.

Silva-Briano M, Arroyo-Bustos G, Beltran-Alvarez R, Adabache-Ortiz A, Galvan de la Rosa R, 2010. [Daphnia Ctenodaphnia lumholtzi G.O. Sars, 1885 (Crustacea: Cladocera); an exotic cladoceran in Mexico].[Article in Spanish with English Abstract]. Hidrobiológica 20:275-280.

Simberloff D, 2010. Invasive species, p. 131-152. In: N.S. Sodhi and P.R. Ehrlich (eds.), Conservation biology for all. Oxford Biology.

Simões NR, Robertson BA, Lansac-Tôha FA, Takahashi EM, Bonecker CC, Velho LFM, Joko CY, 2009. Exotic species of zooplankton in the Upper Paraná River floodplain, Daphnia lumholtzi Sars, 1885 (Crustacea: Branchiopoda). Braz. J. Biol. 69:551-558.

Soberon J, 2007. Grinnellian and Eltonian niches and geographic distribution of species. Ecol. Lett. 10:1115-1123.

Sodhi NS, Brook BW, Bradshaw CAJ, 2009. Causes and consequences of species extinctions, p. 514-520. In: S.A. Leviton (ed.), Princeton guide to ecology. Princeton University Press.

Sousa FDR, Elmoor-Loureiro LMA, Palaoro AV, Silvano DL, 2014. [Predição da invasão de Daphnia lumholtzi (Crustacea, Branchiopoda) na região Neotropical].[Article in Portuguese]. Proceedings 30th Congresso Brasileiro de Zoologia, Porto Alegre.

Speziale K, Lambertucci S, 2010. A call for action to curb invasive species in South America. Nature 467:153-153.

Valdivia-Vilar RS, Burger L, 1989. Description of Daphniopsis marcahuasensis sp. nov. (Cladocera: Daphniidae) from Peru with the inclusion of a key of the genus species. Amazoniana 10:439-452.

Wittmann MJ, Gabriel W, Harz EM, Laforsch C, Jeschke JM, 2013. Can Daphnia lumholtzi invade European lakes? NeoBiota 16:39-57.

Work KA, Gophen M, 1999. Environmental variability and the population dynamics of the exotic Daphnia lumholtzi and native zooplankton in Lake Texoma, U.S.A. Hydrobiologia 405:11-23.

Zanata LH, Espindola ELG, Rocha O, Pereira RHG, 2003. First record of Daphnia lumholtzi (Sars, 1885), exotic cladoceran, in São Paulo State (Brazil). Braz. J. Biol. 63:717-720.

Zanata LH, Espindola ELG, Rocha O, Pereira RHG, 2008. Morphological abnormalities in Cladocera (Branchiopoda) in a cascade of reservoirs in the middle and lower Tietê river (São Paulo, Brazil). Braz. J. Biol. 68:681-682.

Zhang YH, Wang IJ, Comes HP, Peng H, Qiu YX, 2016. Contributions of historical and contemporary geographic and environmental factors to phylogeographic structure in a Tertiary relict species, Emmenopterys henryi (Rubiaceae). Sci. Rep. 6:24041. 